\title{
Second-law analysis of two-stage vapour compression refrigeration plants
}

\section{E. Torrella}

Department of Applied Thermodynamics, Polytechnic University of Valencia, Camino de Vera, 14,

E-46022 Valencia, Spain

E-mail: torrella@ter.upv.es

\section{R. Llopis*, R. Cabello and D. Sánchez}

Department of Mechanical Engineering and Construction, Campus de Riu Sec., Jaume I University,

E-12071 Castellón, Spain

Fax: +34 964728106

E-mail: rllopis@emc.uji.es

E-mail: cabello@emc.uji.es

E-mail: sanchezd@emc.uji.es

${ }^{*}$ Corresponding author

\section{J.A. Larumbe}

Department of Applied Thermodynamics, Polytechnic University of Valencia,

Camino de Vera, 14,

E-46022 Valencia, Spain

E-mail: jalarumbe@ter.upv.es

\begin{abstract}
This paper describes a Second Law Analysis based on experimental data of a two-stage vapour compression facility driven by a compound compressor for medium and low-capacity refrigeration applications, which operates with the most usual inter-stage configurations (direct liquid injection and subcooler). The experimental analysis is performed for an evaporating temperature range between $-36^{\circ} \mathrm{C}$ and $-20^{\circ} \mathrm{C}$ and for a condensing temperature range between $30^{\circ} \mathrm{C}$ and $47^{\circ} \mathrm{C}$ using the refrigerant $\mathrm{R}-404 \mathrm{~A}$. The final results are compared with energy analysis from previous works. Additionally, a new criterion of equivalence between the simple vapour compression cycle and the two-stage compression cycle is given.
\end{abstract}

Keywords: R-404A; exergy analysis; inter-stage pressure; two-stage refrigerating cycle; vapour compression. 
Reference to this paper should be made as follows: Torrella, E., Llopis, R., Cabello, R., Sánchez, D. and Larumbe, J.A. (2010) 'Second-law analysis of two-stage vapour compression refrigeration plants', Int. J. Exergy, Vol. 7, No. 6, pp.641-653.

Biographical notes: Enrique Torrella is a Professor at the Polytechnic University of Valencia (Spain).

Rodrigo Llopis is a Lecturer at the Jaume I University of Castellón (Spain).

Ramón Cabello is a Professor at the Jaume I University of Castellón (Spain).

Daniel Sánchez is a Lecturer at the Jaume I University of Castellón (Spain).

Juan Antonio Larumbe is a Senior Lecturer at the Polytechnic University of Valencia (Spain)

The authors belong to the Thermal Engineering Group (www.git.uji.es), which has published 18 international papers, 32 communications in international congresses and eight textbooks. Their field of research is focused on refrigeration facilities, always based on experimental analysis, and tries to improve their energy efficiency and to introduce natural working fluids such as carbon dioxide.

\section{Introduction}

The authors of this paper dedicate one of their current lines of research to the analysis of two-stage compression cycle facilities featuring compound-type compressors (alternative poly-cylindrical compressors) consisting of several cylinders. In this type of compressors, some of the cylinders compress the refrigerant in the low-pressure side while simultaneously the rest of the cylinders compress the refrigerant in the high-pressure side. Different energy analyses for this type of configuration of a refrigeration facility have been already presented in previous papers (Llopis et al., 2007; Torrella et al., 2009a, 2009b). This paper aims to verify, according to second-law assumptions, the results obtained from an experimental double-stage facility operated with the Subcooler and Direct Liquid Injection system as intermediate configurations and with no treatment in the intermediate level. A second goal of this work consisted of obtaining additional information of the plant using a second-law approach.

The Second Law of Thermodynamics states that mechanical work can be transformed into heat entirety, but conversely, heat cannot be completely turned into mechanical work, which means real processes are not reversible. The degree of irreversibility in a process implies that a certain amount of entropy is created, the higher the degree of irreversibility the higher the amount of entropy generated. Several techniques for the analysis of the degree of irreversibility in a process have been developed, so the efficiency of the energy conversion process can be estimated attending to not only quantity but also quality considerations. This relatively new field in Thermodynamics is commonly referred to as 'Second-Law analysis' or 'Exergy analysis' (Willeboer, 1986). 
The terms 'Exergy' and 'Exergy Analysis' were created by Rant (1963) and its use has been increasing significantly since due to the growing present need to improve the process efficiency in power systems. This type of methodology entails applying the First and Second Law of Thermodynamics simultaneously to the analysis and the design of installations; Bejan (2002) explains the bases of the method and offers some examples on how to carry on the exergy analysis method for analysing and designing installations.

The Exergy Analysis method, when applied to two-stage vapour compression cycles, was intended to find the value of the intermediate pressure that maximises the COP of the cycle (Ouadha et al., 2005), basically in booster-type configurations, thus results of the exergy analysis of a two-stage refrigeration system operating between a constant evaporating temperature of $-30^{\circ} \mathrm{C}$ and condensation temperatures of $30^{\circ} \mathrm{C}, 40^{\circ} \mathrm{C}, 50^{\circ} \mathrm{C}$ and $60^{\circ} \mathrm{C}$ with two natural substitutes of HCFC22, namely propane (R290) and ammonia (R717), as working fluids were presented. The study was performed theoretically on a cycle with an open heat exchanger (flash intercooling). A similar strategy can be found in Zubair et al. (1996). Besides (Khan and Zubair, 1998), thermodynamic models of the two-stage system were developed to simulate system performance in accordance with the intermediate stage temperature and heat-exchanger parameter (installation with flash intercooling was considered as well); in Özgür and Bayrakçi (2008); the effects of temperature changes in the condenser and evaporator on the plant's irreversibility rate were determined (flash intercooling was taken into account one more time). Finally (Nikolaidis and Probert, 1998), the second-law efficiency, coefficient of cooling performance and total Exergy Destruction (ED) of the system variations with the inter-stage pressure are presented graphically, this study presents the first- and second-law analyses of the transcritical two-stage cycle with external intercooling.

In contrast to previous theoretical analysis based on a second-law approach of vapour compression systems, this work includes an exergy study based on experimental data of different inter-stage configurations of double-stage cycles driven by compound compressors. The analysis was performed for an evaporating temperature range between $-36^{\circ} \mathrm{C}$ and $-20^{\circ} \mathrm{C}$ and a condensing range between $30^{\circ} \mathrm{C}$ and $47^{\circ} \mathrm{C}$ using the $\mathrm{R} 404 \mathrm{~A}$ as working fluid. Furthermore, this work presents a new criterion that determines when a two-stage cycle is more suitable than a single-stage compression cycle.

\section{Experimental plant and previous experimental results}

The experimental double-stage vapour compression plant is the same as that used in the works of Llopis et al. (2007) and Torrella et al. (2009a, 2009b) (Figure 1). It consists of three fluid loops in which the main one is the refrigerant one and the rest are auxiliary systems that allow the study of the behaviour of the system under different operating conditions.

The refrigerant circuit, R404A employed as the working fluid, is a two-stage vapour compression cycle with a direct liquid injection system to control the degree of desuperheat between the compression stages and a subcooler to subcool the liquid refrigerant. The refrigerant is driven by a $4 \mathrm{~kW}$ semi-hermetic compound compressor with six cylinders (bore: $50.8 \mathrm{~mm}$; stroke: $31.8 \mathrm{~mm}$ ); four of the cylinders work in the 
low-pressure side and the rest in the high-pressure one. The refrigerant coming from the high-pressure stage undergoes condensation in a brazed-plate heat exchanger with a heat transfer surface area of $0.62 \mathrm{~m}^{2}$, and it feeds the liquid receiver of the facility. The evaporator corresponds to a brazed-plate heat exchanger with heat transfer surface area of $1.24 \mathrm{~m}^{2}$ and it is controlled by a thermostatic expansion valve with external equalisation. The facility has an accumulation tank to avoid problems related to liquid suction in the compressor at the evaporator outlet. The plant incorporates two intermediate systems: the direct liquid injection system, which is composed of a thermostatic expansion valve, whose bulb is placed at the compressor entry, which allows the regulation of the inlet temperature at the compressor at the second compression stage; the subcooler, which is composed of a brazed-plate heat exchanger, with a heat-transfer surface area of $0.29 \mathrm{~m}^{2}$, and a thermostatic expansion valve, which allows to subcool the liquid refrigerant coming from the condenser by means of the evaporation of a part of this refrigerant in the subcooler.

Figure 1 Schematic plant's diagram (see online version for colours)

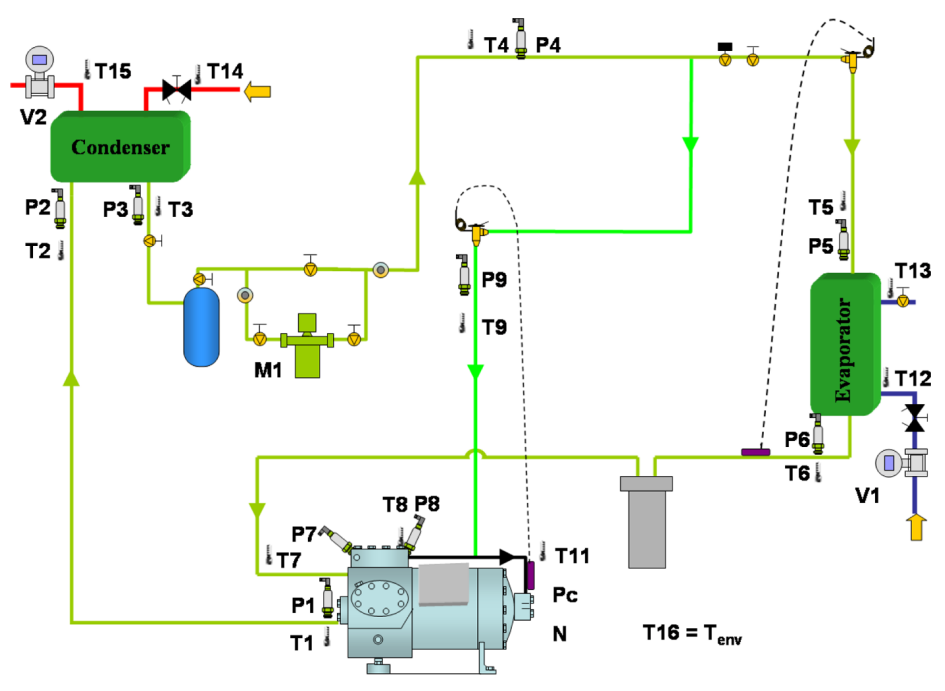

The refrigerant load to the plant is provided with an auxiliary system that employs a brine (ethylene-glycol/water $50 / 50 \%$ by vol.). This auxiliary system consists of a 500-litre secondary fluid tank heated with electrical resistors (controlled by a PID regulator) and an inverter drive for the pump to control the flow rate. This way a constant temperature in the tank and the regulation of the evaporating pressure value are allowed. On the other hand, to control the condensing pressure, another auxiliary system is used. This system consists of a loop working with water that absorbs the heat released in the condenser by the refrigerant. After flowing out from the condenser, the water is cooled again by air-cooled heat exchangers. These heat exchangers are controlled by an inverter drive for the fan motor to obtain the required temperature level. Another inverter drive is used for the pump.

The thermodynamic properties of the working fluid are obtained using 16 T-type thermocouples placed over the pipe surface and nine piezoelectric pressure transducers. Mass flow rates are obtained using a Coriolis mass flow-metre for the main working fluid, and two magnetic volumetric flow-metres for the secondary fluids or brines. 
The compressor power consumption is determined using a digital wattmeter, and its speed is acquired using a signal from the inverter drive, which was calibrated using a frequency analyser with an accelerometre placed over the compressor cylinders. All sensors were calibrated and their uncertainties are those shown in Table 1. All the signals are gathered by a data acquisition system and handled online using a LABVIEW-based application that uses REFPROP dynamic routines (Lemmon et al., 2002) to obtain the thermodynamic properties of the refrigerant and water, and interpolated polynomials from the 2005 ASHRAE Handbook Fundamentals (ASHRAE, 2005) for the properties of the ethylene-glycol mixture.

Table 1 Measurement device uncertainties

\begin{tabular}{llll}
\hline Physical variable & Measurement device & $\begin{array}{l}\text { Measurement and } \\
\text { calibration range }\end{array}$ & $\begin{array}{l}\text { Calibrated } \\
\text { uncertainty }\end{array}$ \\
\hline $\begin{array}{l}\text { Temperature } \\
\text { Pressure }\end{array}$ & $\begin{array}{l}\text { T-type thermocouples } \\
\text { Pressure gauges }\end{array}$ & -60 to $150^{\circ} \mathrm{C}$ & $\pm 0.1^{\circ} \mathrm{C}$ \\
& $0-1000 \mathrm{kPa}$ & $\pm 10 \mathrm{kPa}$ \\
$\begin{array}{l}\text { Refrigerant mass flow rate } \\
\begin{array}{l}\text { Secondary fluid volumetric } \\
\text { flow rates }\end{array}\end{array}$ & $\begin{array}{l}\text { Magnetic volumetric } \\
\text { flow metre }\end{array}$ & $0-3000 \mathrm{kPa}$ & $\pm 30 \mathrm{kPa}$ \\
$\begin{array}{l}\text { Compressor power } \\
\text { consumption }\end{array}$ & Digital wattmetre & $0-6 \mathrm{~kg} \cdot \mathrm{min}^{-1} \cdot \mathrm{min}^{-1}$ & $\pm 0.22 \%$ of reading \\
\begin{tabular}{l} 
Compressor speed \\
\hline
\end{tabular} & Inverter signal & $0-1500 \mathrm{rpm}$ & $\pm 0.33 \%$ of reading \\
\hline
\end{tabular}

The experimental analysis of the facility focuses on an analysis of the performance of R404A in three different two-stage vapour compression configurations (Figure 2). The Base configuration corresponds to a two-stage vapour compression cycle with no arrangements at intermediate pressure. The two-stage vapour compression cycle configuration with a subcooling stage is called Subc. In the Subc configuration, a brazed-plate heat exchanger subcools the refrigerant flowing out of the condenser by means of a part of this refrigerant, which is expanded by a thermal expansion valve. The evaporation process in the subcooler is controlled by a thermostatic expansion valve, which also manages to desuperheat the refrigerant between the compression stages since the refrigerant employed for the subcooling process is injected in the form of superheated/reheated vapour between both compression stages. Finally, Inj goes for the two-stage vapour compression cycle configuration with the direct liquid injection system in which a fraction of the refrigerant flow at the condenser outlet is used to get a major desuperheat between the compression stages.

All the experimental COP data collected during the experimental tests carried out with different condensing and evaporating pressures are shown in Figures A1 and A2 of Annex 1, and the compressor power consumption and cooling capacity on Figures A3 and A4, respectively. The highest COP values were obtained for the Subc configuration, followed by the ones for the Base configuration and the values for the Inj configuration, respectively; being the Inj configuration COP the lowest one of all. Further information on the energy analysis can be found in the works of Llopis et al. (2007) and Torrella et al. (2009b). 
Figure 2 Two-stage configurations analysed in this work

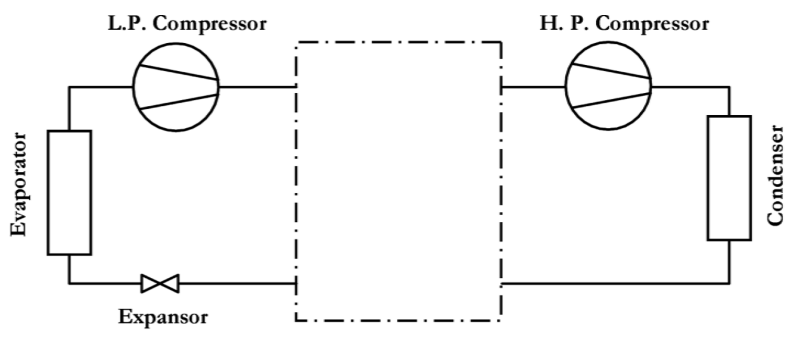

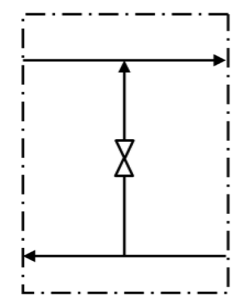

Direct Liquid Injection Configuration

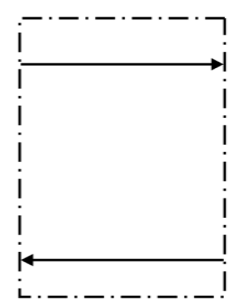

Base configuration

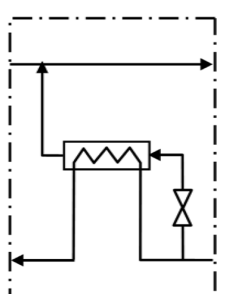

Subcooler Configuration

\section{Second-law analysis}

First of all, ED for the control volume at the intermediate pressure (Figure 3) is taken into account. The exergy balance for a control volume undergoing steady-state process is expressed as represented by equation (1) (Arora and Kaushik, 2008).

$$
\begin{aligned}
\mathrm{ED}_{i}= & \sum(\dot{m} \cdot e)_{\text {in }}-(\dot{m} \cdot e)_{\text {out }}+\sum\left[\sum\left(\dot{Q} \cdot\left(1-\frac{T_{M}}{T}\right)\right)_{\text {in }}-\sum\left(\dot{Q} \cdot\left(1-\frac{T_{M}}{T}\right)\right)_{\text {out }}\right] \\
& \pm \sum P_{C} .
\end{aligned}
$$

Figure 3 Control volume of the inter-stage pressure zone

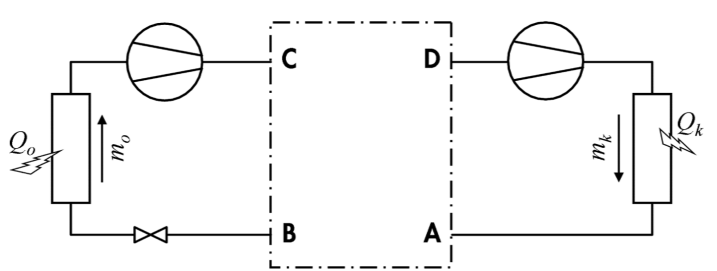

Heat transfer to the surroundings is negligible, so the balance equation can be expressed as equation (2).

$$
\mathrm{ED}_{i}=\dot{m}_{k} \cdot e_{A}-\dot{m}_{k} \cdot e_{D}+\dot{m}_{o} \cdot e_{C}-\dot{m}_{o} \cdot e_{B} .
$$

Considering the Base configuration, no effect in the connexion pipes is considered, so we can assume that $A=B, D=C$ and $m_{k}=m_{o}$, which leads to a null ED rate in the inter-stage zone:

$$
\mathrm{ED}_{\text {Base }}=0 .
$$


In the case of the Inj configuration, the properties at the points $\mathrm{D}$ and $\mathrm{C}$ are not equal, furthermore the mass flow rate through condenser and evaporator differ, and therefore the ED in the inter-stage zone can be expressed as equation (4).

$$
\begin{aligned}
\mathrm{ED}_{I n j}= & \dot{m}_{k} \cdot e_{A}-\dot{m}_{k} \cdot e_{D}+\dot{m}_{o} \cdot e_{C}-\dot{m}_{o} \cdot e_{B} \\
= & {\left[\dot{m}_{k} \cdot h_{A}-\dot{m}_{k} \cdot h_{D}+\dot{m}_{o} \cdot h_{C}-\dot{m}_{o} \cdot h_{B}\right] } \\
& -T_{M} \cdot\left[\dot{m}_{k} \cdot s_{A}-\dot{m}_{k} \cdot s_{D}+\dot{m}_{o} \cdot s_{C}-\dot{m}_{o} \cdot s_{B}\right] .
\end{aligned}
$$

The energy balance on the collector prior to the high-pressure compressor inlet is expressed as follows:

$$
\dot{m}_{k} \cdot h_{A}-\dot{m}_{k} \cdot h_{D}+\dot{m}_{o} \cdot h_{C}-\dot{m}_{o} \cdot h_{B}=0
$$

And consequently, the ED ratio for the Inj configuration can be represented using the relation (4) by equation (6).

$$
\begin{aligned}
\mathrm{ED}_{I n j} & =-T_{M} \cdot\left[\dot{m}_{k} \cdot s_{A}-\dot{m}_{k} \cdot s_{D}+\dot{m}_{o} \cdot s_{C}-\dot{m}_{o} \cdot s_{B}\right] \\
& =T_{M}\left\{\dot{m}_{o} \cdot\left[\frac{\dot{m}_{k}}{\dot{m}_{o}} \cdot\left(s_{D}-s_{A}\right)+\left(s_{B}-s_{C}\right)\right]\right\} .
\end{aligned}
$$

If the exergy analysis is applied for the Subc configuration, an expression equivalent to equation (6) is obtained, however, in this case the properties at the points do not match with the Inj configuration.

The results are shown graphically in Figure 4 for the condensing pressure variation test and in Figure 5 for the evaporating pressure variation test. In Figures 4 and 5, the ED rate divided by the dead state temperature is represented. As shown in the representation, there is only degradation for the configurations with some kind of intermediate arrangement, reaching the highest values of ED in the case of the $S u b c$ configuration and the lowest ones in the Inj configuration. Evidently, there is no ED in the Base configuration (equation (3)).

Figure 4 Exergy destruction vs. condensing pressure $\left(P_{o}=160 \mathrm{kPa}\right)$

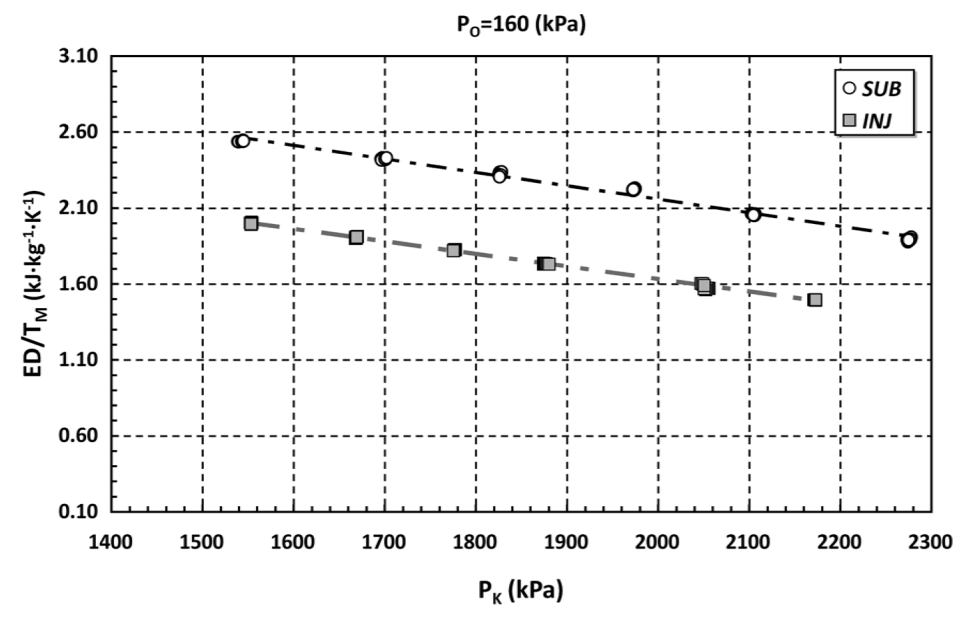


Figure 5 Exergy destruction vs. evaporating pressure $\left(P_{k}=1830 \mathrm{kPa}\right)$

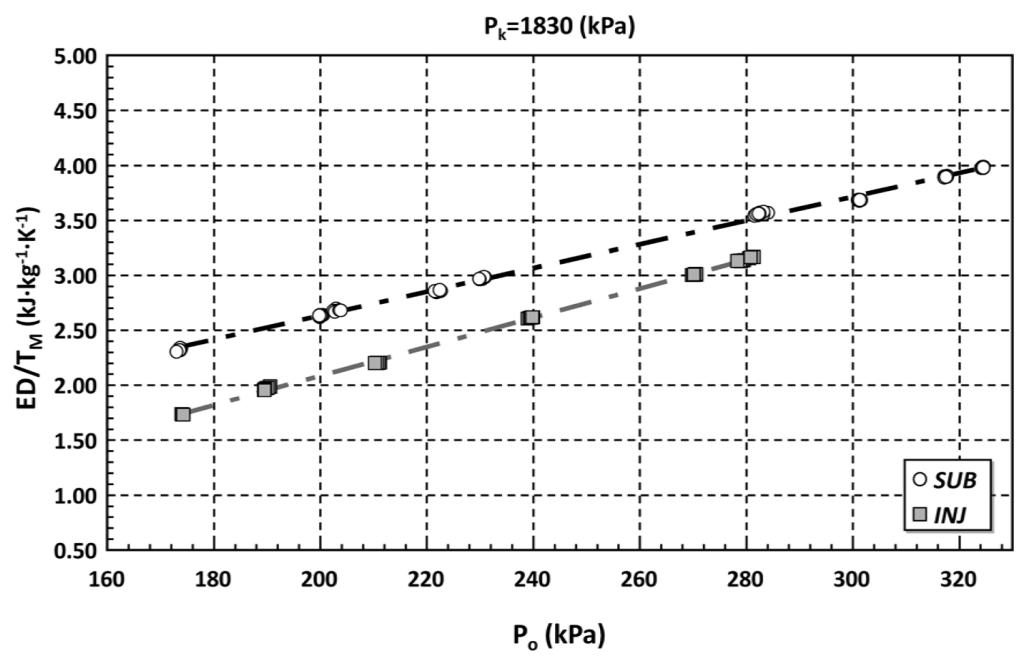

Clearly, if the COP values are the highest for the Subc configuration (Annex 1, Figures A1 and A2), despite the ED values being the highest ones for this configuration, the irreversibility in the rest of the installation should be the lowest.

To prove this hypothesis, an overall energy balance for the installation ought to be considered (equation (7)).

$$
\dot{Q}_{k}=\dot{Q}_{o}+\sum P_{C}
$$

The expression (7) is purely approximate since neither effects in pipes nor the cooling in the electric motor driving the semi-hermetic compressor, which occurs right before the admission of vapours in the high-pressure stage, are considered. This assumption will not yield a big overall error, since it is not higher than an $8 \%$ of the relative error, as shown in Figure 6.

Figure 6 Deviation from the first principle

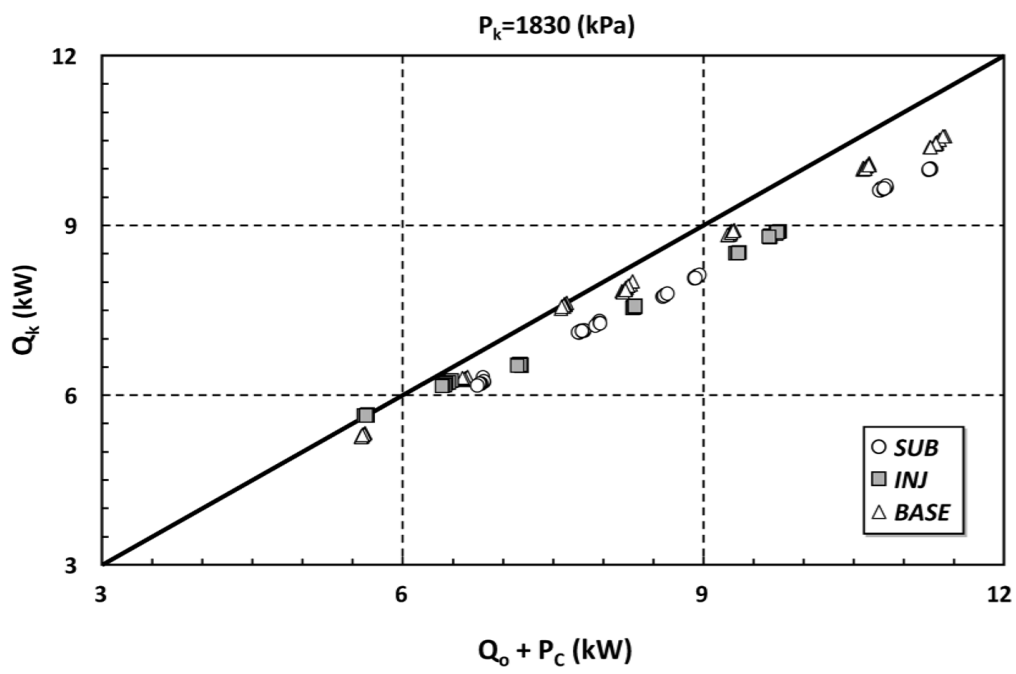


The divergence noticed in the expression of the First Law of Thermodynamics shows that the total dissipated power in the condenser is less than the sum of the dissipated power in the evaporator and the power consumption in the generator, which is due to the cooling occurring to the electrical motor between the compression stages and due to heat transfer from the pipes to the environment. Obviously, the higher the power (higher evaporating temperature), the higher the divergence mentioned before.

Neglecting the error in the overall balance and according to the Second Law of Thermodynamics, expression (8) can be written.

$$
\Delta s=\frac{\dot{Q}_{K}}{T_{F C}}-\frac{\dot{Q}_{0}}{T_{F F}} \geq 0 .
$$

And combining both expressions of the laws (7) and (8):

$$
\begin{aligned}
\frac{\dot{Q}_{0}}{T_{F C}}+ & \frac{\sum P_{C}}{T_{F C}}-\frac{\dot{Q}_{0}}{T_{F F}} \geq 0 \rightarrow \sum P_{C} \cdot\left[\frac{\mathrm{COP}}{T_{F C}}+\frac{1}{T_{F C}}-\frac{\mathrm{COP}}{T_{F F}}\right]=\Delta s \geq 0 \rightarrow \\
& \rightarrow \frac{\sum P_{C}}{T_{F C}} \cdot\left[-\mathrm{COP} \cdot\left(\frac{T_{F C}-T_{F F}}{T_{F F}}\right)+1\right]=\frac{\sum P_{C}}{T_{F C}} \cdot\left[1-\frac{\mathrm{COP}}{\varepsilon}\right]=\Delta s \geq 0
\end{aligned}
$$

being $\varepsilon$ the COP for the Carnot Cycle operating between ' $T_{F C}$ ' and ' $T_{F F}$ ' $\left(\varepsilon=T_{F F}\right.$ / $\left.\left(T_{F C}-T_{F F}\right)\right)$.

The correlation between the total compression ratio and the entire entropy generated in the whole cycle (evaluated from the experimental data with equation (9) and using the evaporating pressure variation test, Figures A2 and A4) is presented graphically in Figure 7. It can be observed that the entropy generated decreases with the increment in the total compression ratio. This trend is related with the decrease in the refrigerant mass flow rate through the low-compression stage when the evaporating temperature goes down, i.e., at high compression ratios. The most efficient configuration, either from an exergy or from an energy point of view (Figures 7 and A2, respectively), corresponds to the Subcooler configuration, which presents the upper efficiency especially at high-compression ratios or low evaporating pressures.

Figure 7 Entropy generation for each configuration vs. total compression ratio $\left(P_{k}=1830 \mathrm{kPa}\right)$

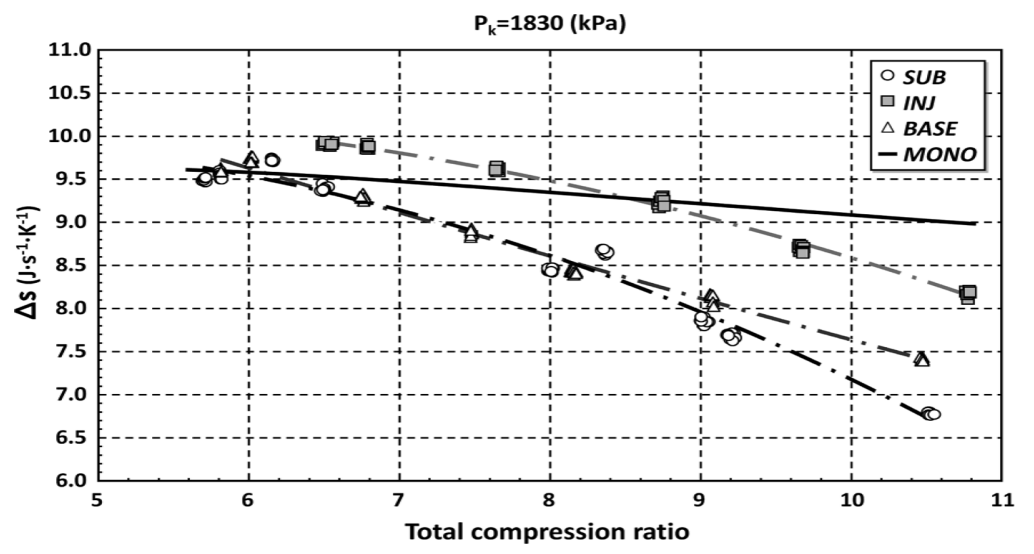


In addition, the theoretical study of a single vapour compression cycle configuration, referred as Mono, has been included in this work. With the purpose of establishing a comparison between a single configuration (one compression stage) and all the two-stage compression configurations analysed in this work, the following assumptions were made for the single vapour compression cycle configuration:

- a geometric volumetric flow equal to the flow in the compound compressor cylinders in its low-pressure stage

- a volumetric efficiency similar to the variation noticed in the compound compressor at its total compression rate.

The total entropy generated by the single-stage compression cycle is represented in Figure 7 with regard to the total compression ratio. Figure 7 shows that the entropy generated in the Mono configuration is higher than the entropy generated in the two-stage configurations Subc and Base for total compression ratios higher than 6, and higher than the entropy generated in the Inj configuration for a total compression ratio value higher than 8.5 approximately.

Either for the COP value analysis or for the second-law analysis, the Inj configuration produced the most unfavoured results; however, this configuration brings in a very significant advantage, the important desuperheating produced during the suction in the high-pressure stage that lowers the discharge temperature of the compressor. This fact can be useful when working with refrigerants reaching high temperatures during the compression process. This is of no particular importance when working with R-404, though.

\section{Conclusions}

In this work, a Second-Law Analysis, based on experimental data, of a two-stage vapour compression refrigeration plant operated with a compound compressor has been presented. The analysis, which focused on different inter-stage configurations (direct liquid injection and subcooler), was performed in a wide condensing and evaporating temperature range using the R404A as working fluid.

The energy analysis for the different configurations reveals that the best COP values were achieved by the Subc configuration followed by the Base configuration whilst the lowest COP values were achieved while operation in the Inj configuration mode. This trend can be noted either for the variation of condensing pressure or for the variation of the evaporating pressure.

Regarding the Second-Law Analysis, it can be observed that the exergy in the intermediate stage is higher for the Subc configuration than for the Inj configuration, being zero for the Base configuration.

Lastly, the comparison of the total entropy generated in each installation sustains the results from the previous energy analysis and allows the introduction of a criterion for the conversion between the single compression cycle configuration and two-stage compression cycle configurations. The latter, along the introduction and consideration of the single compression cycle configuration, proved that for total compression ratio values higher than 6 is convenient to put into operation a subcooling stage for multiple compression stage or no intermediate arrangements at all. For total compression ratio, 
values higher than 8.5 two-stage compression configurations with injection should be considered.

\section{Acknowledgements}

The authors are indebted to the Spanish Ministry of Education and Science (CTM2008-06468-C02-02/TECNO) and to the Spanish Ministry of the Environment and Rural and Marine Affairs (200800050084716) for their economic support to this work.

\section{References}

Arora, A. and Kaushik, S.C. (2008) 'Theoretical analysis of a vapour compression refrigeration system with R502, R404A and R507A', Int. Journal of Refrigeration, Vol. 31, pp.998-1005.

ASHRAE (2005) 2005 Handbook-Fundamentals, American Society of Heating, Refrigerating and Air Conditioning Engineers, Inc., Atlanta.

Bejan, A. (2002) 'Fundamentals of exergy analysis, entropy generation minimization, and the generation of flow architecture', Int. J. Energy Research, Vol. 26, pp.545-565.

Khan, J. and Zubair, S.M. (1998) 'Design and rating of a two-stage vapour compression refrigeration system', Energy, Vol. 23, No. 10, pp.867-878.

Lemmon, E.W., McLinden, M.O. and Huber, M.L. (2002) REFPROP NIST Standard Reference Database 23, v.7.0, National Institute of Standards, Gaithersburg, MD, USA.

Llopis, R., Torrella, E., Cabello, R. and Larumbe, J.A. (2007) 'Experimental energetic analysis of the liquid injection effect in a two-stage refrigeration facility using a compound compressor', $H V A C \& R$ Research, Vol. 13, No. 5, pp.819-831.

Nikolaidis, C. and Probert, D. (1998) 'Exergy-method analysis of a two-stage vapour-compression refrigeration-plants performance', Applied Energy, Vol. 60, pp.241-256.

Ouadha, A., En-nacer, M., Adjlout, L. and Imine, O. (2005) 'Exergy analysis of a two-stage refrigeration cycle using two natural substitutes of HCFC22', Int. Journal of Exergy, Vol. 2, No. 1, pp.14-30.

Özgür, A.E. and Bayrakçi, H.C. (2008) 'Second law analysis of two-stage compression transcritical $\mathrm{CO}_{2}$ heat pump cycle', Int. J. Energy Research, Vol. 32, pp.1202-1209.

Rant, Z. (1963) 'Die Heiztechnik und der zweite Hauptsatz der Thermodynamik', Gaswärme International, Vol. 12, No. 1, pp.297, 304.

Torrella, E., Llopis, R. and Cabello, R. (2009a) 'Experimental evaluation of the inter-stage conditions of a two-stage refrigeration cycle using a compound compressor', Int. Journal of Refrigeration, Vol. 32, pp.307-315.

Torrella, E., Llopis, R., Cabello, R. and Sánchez, D. (2009b) 'Experimental energetic analysis of the subcooler system in a two-stage refrigeration facility driven by a compound compressor', HVAC\&R Research, Vol. 15, No. 3, pp.583-596.

Willeboer, W. (1986) On the Applications of Energy Analysis and Second Law Analysis, Eindhoven University of Technology, Report EUT/BDK/20, ISBN 90-6787-021-4, Eindhoven.

Zubair, S.M., Yaqub, M. and Khan, S.H. (1996) 'Second-law-based thermodynamic analysis of two-stage and mechanical-subcooling refrigeration cycles', Int. Journal of Refrigeration, Vol. 19, No. 8, pp.506-516. 


\section{Nomenclature}

\begin{tabular}{ll}
\hline$e$ & Specific exergy $\left(\mathrm{kJ} \cdot \mathrm{kg}^{-1}\right)$ \\
$\mathrm{ED}$ & Exergy Destruction rate $(\mathrm{kW})$ \\
$h$ & Specific enthalpy $\left(\mathrm{kJ} \cdot \mathrm{kg}^{-1}\right)$ \\
$\dot{m}$ & Mass flow rate $\left(\mathrm{kg} \cdot \mathrm{s}^{-1}\right)$ \\
$P$ & Pressure $(\mathrm{Pa})$ \\
$P_{C}$ & Compressor power consumption $(\mathrm{kW})$ \\
$\dot{Q}$ & Heat transfer rate $(\mathrm{kW})$ \\
$s$ & Specific entropy $\left(\mathrm{J} \cdot \mathrm{kg}^{-1} \cdot \mathrm{K}^{-1}\right)$ \\
$T$ & Temperature $(\mathrm{K})$ \\
$t$ & Compression ratio \\
Greek symbols & \\
$\varepsilon$ & Carnot cycle COP \\
Subscripts & \\
$o$ & Evaporator \\
$F C$ & High-temperature heat sink \\
$F F$ & Low-temperature heat source \\
$M$ & Dead state \\
$K$ & Condenser \\
$i$ & Each configuration \\
Superscripts & \\
Base & Refers to the two-stage configuration without inter-stage systems \\
Inj & Refers to the two-stage configuration with the direct liquid injection system \\
Mono & Refers to a single-stage vapour compression cycle \\
Subc & Refers to the two-stage configuration with subcooler \\
\hline &
\end{tabular}

\section{Annex 1: Results from the energy analysis}

Figure A1 COP vs. condensing pressure $\left(P_{o}=160 \mathrm{kPa}\right)$

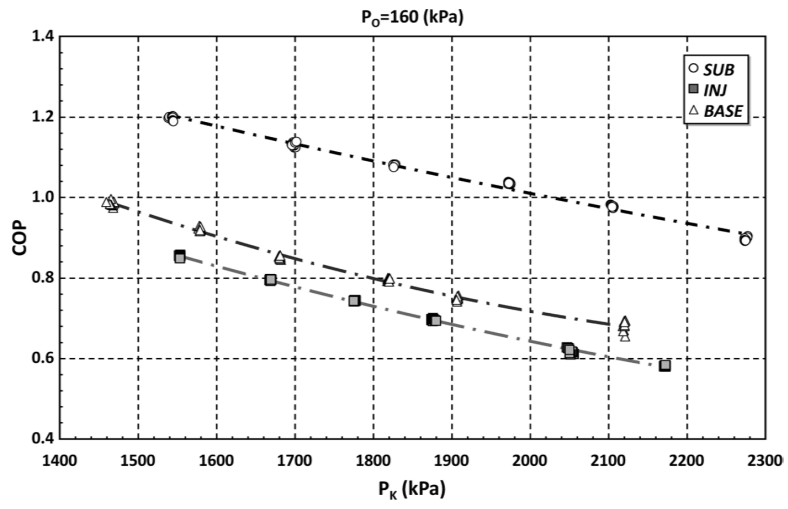

Source: Llopis et al. (2007) and Torrella et al. (2009a, 2009b) 
Figure A2 COP vs. evaporating pressure $\left(P_{k}=1830 \mathrm{kPa}\right)$

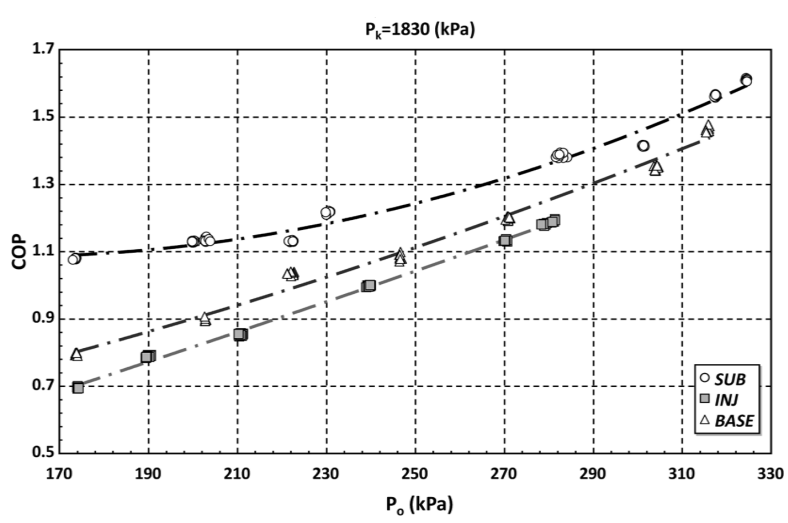

Source: Llopis et al. (2007) and Torrella et al. (2009a, 2009b)

Figure A3 Compressor power consumption vs. evaporating pressure $\left(P_{k}=1830 \mathrm{kPa}\right)$

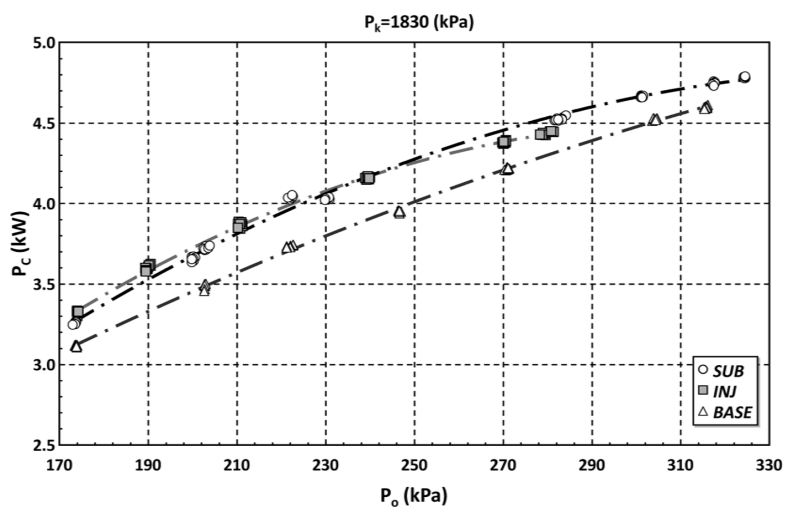

Source: Llopis et al. (2007) and Torrella et al. (2009a, 2009b)

Figure A4 Cooling capacity vs. evaporating pressure $\left(P_{k}=1830 \mathrm{kPa}\right)$

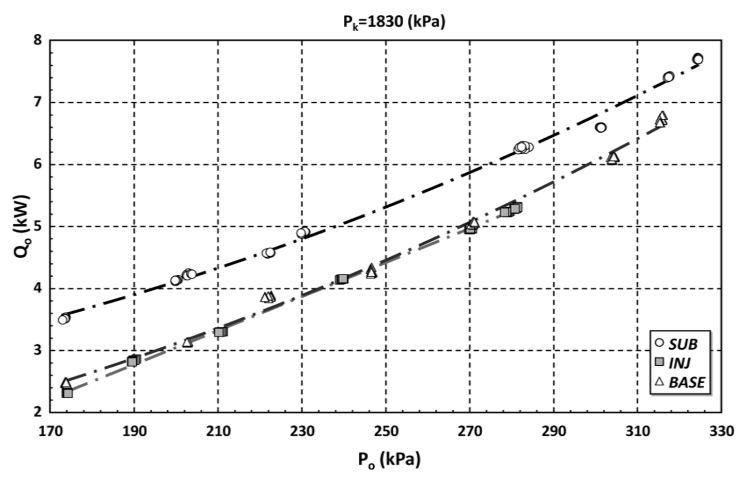

Source: Llopis et al. (2007) and Torrella et al. (2009a, 2009b) 